\title{
APPLICATION POSSIBILITIES OF THERMOVISION TECHNIQUE IN DIAGNOSTICS OF AERIAL SYSTEMS OF RADIO TRANSMITTERS
}

\author{
Milan Šimko ${ }^{1}$, Ján Michalík ${ }^{2}$, Milan Chupáč ${ }^{3}$ \\ Dept of Measurements and Applied Electrical Engineering, University of Žilina, \\ Univerzitná 1, 01026 Žilina, Slovak Republic \\ E-mails: ${ }^{1}$ simko@fel.utc.sk, ${ }^{2}$ dekan@fel.utc.sk, ${ }^{3}$ chupac@fel.utc.sk
}

Received 23 October 2006; accepted 4 December 2006

\begin{abstract}
The paper deals with possibilities of use of thermovision technique in diagnostics of aerial systems of radio transmitters. Graphically presented: heating characteristic of the junction at the transmitter power of $60 \%$ (slack and polluted junction); relationship between temperature of connection (feeder - line, capacitor frame) spacing collar and power; relationship between temperature rise amount of connection and feeder line upon power; thermogram of the junction feeder line - spacing collar, capacity frame; thermogram of the junction feeder line - spacing collar.
\end{abstract}

Keywords: thermovison, radio transmitters, aerial system, spacing collar, junction, thermogram.

\section{Introduction}

Radiocommunications are subject to the incessant development, which requires demanding and innovation activities, because they with their subsidiary plants complete communication background with all the time wider range of expanding radiocommunicational services. One of the providing services is a local, regional, national wide and foreign broadcasting in the band of SW, MW and VSW for the operator, by means of radio transmitters. For the correct acting of these transmitters besides the restoration and reconstruction, their maintenance is of the same importance.

At present, one of the new modern methods utilized not only in diagnostics, research and development but also in monitoring or control of production is the method of thermal fields representation.

From the period when the first thermovision system has been introduced into the market, a qualitative leap forward has been observed so far not only in construction and make of optical - mechanical parts of system cameras, but mainly in electrical circuits, mode of signal processing and in possibility of utilization of powerful software products for various kinds of application.

Nowadays some of leading major producers of infrared technique come to the market with the brand new design of the cameras that are in general, for many aspects a break with tradition in thermovision technique. These cameras most importantly by their technical parameters became favourable choice for contactless measurement and display of temperatures.

\section{Theoretical analysis}

Since thermography has inestimable advantage over other diagnostic methods, because it is a contactless method of temperature difference detection (also of minimal ones) on measured objects, which can be performed during a usual operation, it can be utilized in diagnostics of aerial systems of radio transmitters.

Relatively complicated aerial systems are very sensitive to becoming worse because of transition resistances of particular aerial nodes. Emitted power of the transmitter decreases with worsening of transition resistances and thermal losses arise on the transitions. Regular inspections are needed for the perfect working of the system. These inspections are relatively time demanding and expensive because operations in heights is the matter. Inspections are considerably simplified and shortened just by use of thermovision diagnostics, which result in considerable finance saving.

For the heating calculation of connection (e. g. feeder line - capacitor frame, spacing collar, etc.) these criterions are respected:

- $\quad$ transmitted power during the measurement;

- $\quad$ wind speed influence on the measured heating magnitude.

Concerning the heating determination we come out for a greater approach from the analogy of the solving the dependence between the electrical current, temperature and time and, in our case, between electrical current and heating. Though the solving of the dependence between electrical current and heating is considerably complicated, we can afford briefly to indicate it $[1,2]$. 
For the solving of bare conductor heating by the constant electrical current these assumptions are considered:

a) current distribution in the conductor section is uniform,

b) the conductor is homogenous and linear,

c) the solution for small heating; the radiation influence is not in force in this case,

d) there is the same temperature in all points of the conductor lengthwise.

Then the solution for the element of the length $d x$ is given by the equation of the thermal balance (Fig 1)

$$
d Q_{2}+d Q=d Q_{1}+d Q_{3}+d Q_{4},
$$

where $d Q$ - heat in the element (e.g. terminal); $d Q_{1}-$ heat really ,heating“(terminal); $d Q_{2}=d Q_{3}$ - heat dissipated from the terminal into the conductor; $d Q_{4}-$ heat dissipated into the surroundings; $d Q_{5}$ - heat radiated into the surroundings.

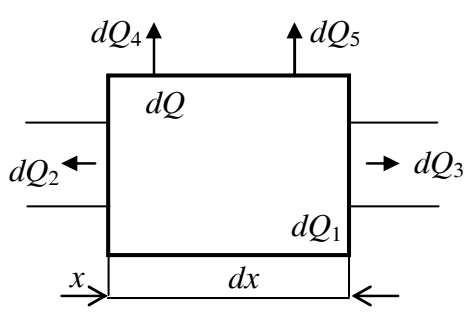

Fig 1. Thermal balance illustrated schematically

On the assumption that alongside the conductor there is no thermal downfall, that is if

$$
d Q_{2}=d Q_{3},
$$

then the equation is arranged into the form

$$
d Q=d Q_{1}+d Q_{4} .
$$

By subsequent solution after substituting for the individual heats we can get the resulting equation for the temperature rise in the dependence on time

$$
\Delta v(t)=\Delta v_{0}+\left(\Delta v_{0}-\Delta v_{\infty}\right) e^{-\frac{t}{\tau}}
$$

where for $\Delta v(t)=0$ we get

$$
\Delta v(t)=\Delta v_{\infty}\left(1-e^{-\frac{\mathrm{t}}{\tau}}\right),
$$

where $\tau$ - time constant; $\Delta v_{0}-$ temperature rise at time $t=0 ; \Delta v_{\infty}-$ temperature rise in the stable state.

In connection with the theoretical analysis a set of experimental measurements was realized from examination of the junctions heating dependence: spacing collars - feeder line, capacitor frames, tension gears, contacts of switches and things like that, in dependence on the transmitter power.

\section{Experimental results}

We realized the measurement during three year seasons (spring, summer, autumn) by thermovision camera AGEMA 550 with the accessories, while temperatures were monitored by pyrometer, too [2].

In Fig 2 there is the course of the heating characteristic of the junction feeder line - spacing collar, capacitor frame at the transmitter power of $60 \%$ (connection not being in good state). We can see that heating characteristic process corresponds to the relation (5).

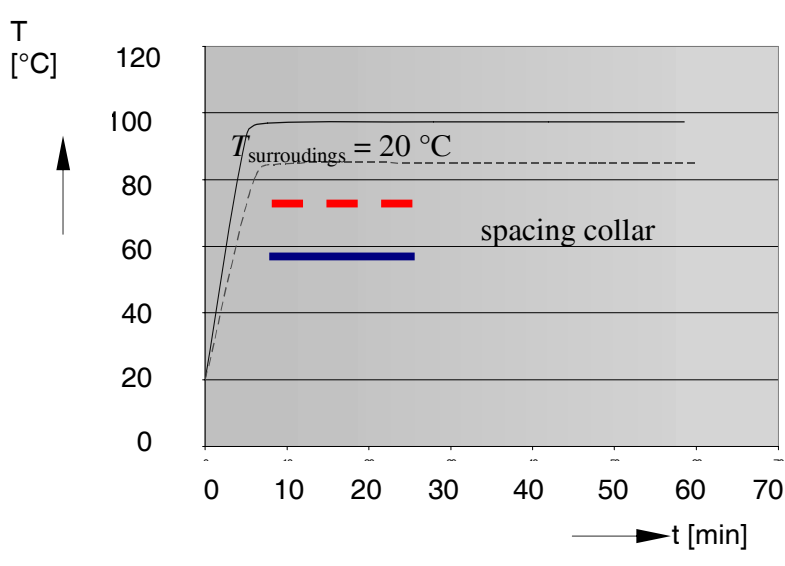

Fig 2. Heating characteristic of the junction at the transmitter power of $60 \%$ (slack and polluted junction)

There is the temperature dependence in Fig 3 of the junction (feeder line - spacing collar, capacitor frame) and feeder line on the transmitter power in case of the junction being in order (drawn up and clear).

We can state that if the junction feeder line - capacitor frame, spacing collar and the like, is in order, which is in good stage, drawn up and clean, it must not be warmer than the feeder line to which it is connected.

The heating characteristics of the junctions in dependence on the transmitted power are shown in Fig 4. The values of junctions heating against the feeder line, that is $\Delta t=T_{s p}-T_{1}$, which are plotted in the graph were obtained as follows: junctions temperatures $\left(T_{s p}\right)$ are the temperatures measured, and for the feeder lines temperatures $\left(T_{1}\right)$ data acquired from dependence measurements in Fig 3 were used.

In the case that the junction is slacked or polluted the temperature increase in relationship with transmitting wave power has a parabolic characteristic.

In Fig 5, there is an example of a thermogram realized on the KW transmitter working at $f=11990 \mathrm{kHz}$, whose transmitter power was $250 \mathrm{~kW}$. The measurement has been performed during a summer period, when temperature of feeder line (Fig 6, ARO 4) is $T_{1}=20,3^{\circ} \mathrm{C}$. Temperature of junction (ARO 1, ARO 2) feeder line-spacing collar is in the first case $T_{s p}=20,5^{\circ} \mathrm{C}$ and in the second case $T_{s p}=20,4^{\circ} \mathrm{C}$. Temperature of junction (ARO 3 ) feeder line - capaci- 
tor frame is $T_{s p}=20,2^{\circ} \mathrm{C}$. As it results from the previous analysis and from Fig 3 , the temperature rise of junction (defined as $\Delta t=T_{s p}-T_{1}$ ) is $\Delta t=0,2{ }^{\circ} \mathrm{C}$ in the case of ARO $1, \Delta t=0,1^{\circ} \mathrm{C}$ in the case of ARO 2 and $\Delta t=-0,1^{\circ} \mathrm{C}$ in the case of ARO 3.

It is possible to state, that the temperature rise is of a very small value and the junction is in good condition. In the case of ARO 3 it attains a lower value than in the case of a feeder line, as it is borne out by the theoretical analysis. The temperature growth of a junction is lower than the temperature growth of a feeder line. The junction because of its bigger surface has bigger ventilating losses and therefore it is better cooled down by air circulation than the feeder line.

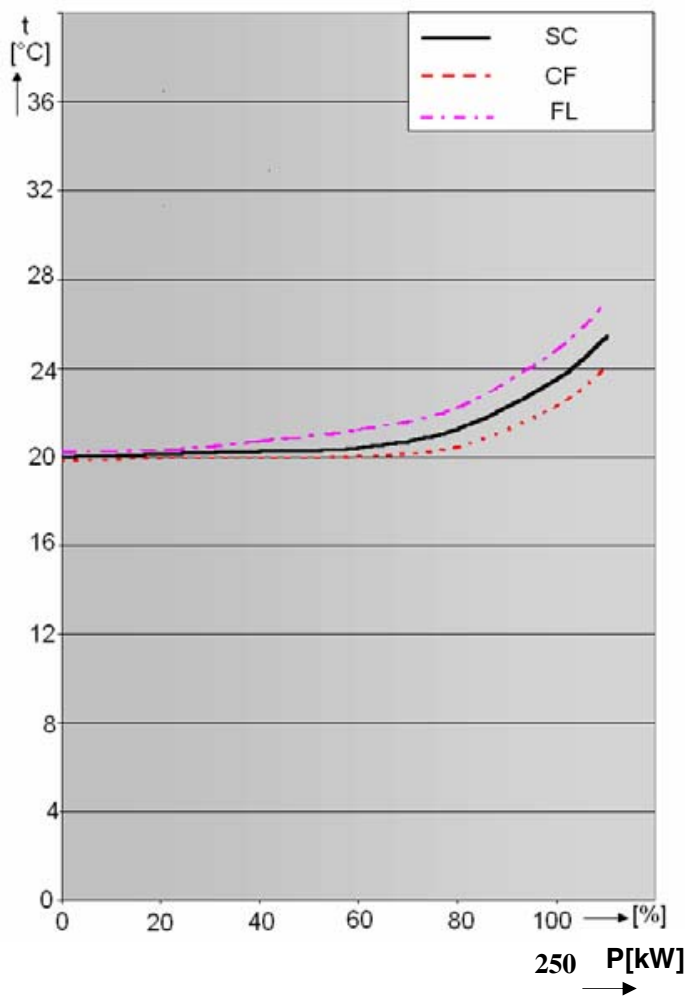

Fig 3. Relationship between temperature of connection (feeder - line, capacitor frame) spacing collar and power.

Connection I drawn up and clean, SC - spacing collar, $\mathrm{CF}$ - capacitor frame, $\mathrm{FL}$ - feeder line

In Fig 6, the area of defect is localized in feeding distribution of antenna, i.e. feeder line-spacing collar, where increased value of the temperature rise $\Delta t=T_{s p}-T_{1}=101^{\circ} \mathrm{C}$ is recorded. During the inspection it is necessary, however, to pay particular attention to antenna itself and to other parts of antenna transmitters.

The recorded or calculated values of temperature rise are, on the basis of their size, divided into several classification scales, to which the grades of measures for localized defects eliminating are recommended. During the measurement, it is necessary to respect the influence of wind speed, fog and further recommendations which have to be part of processed measurement methodology [2, 3].

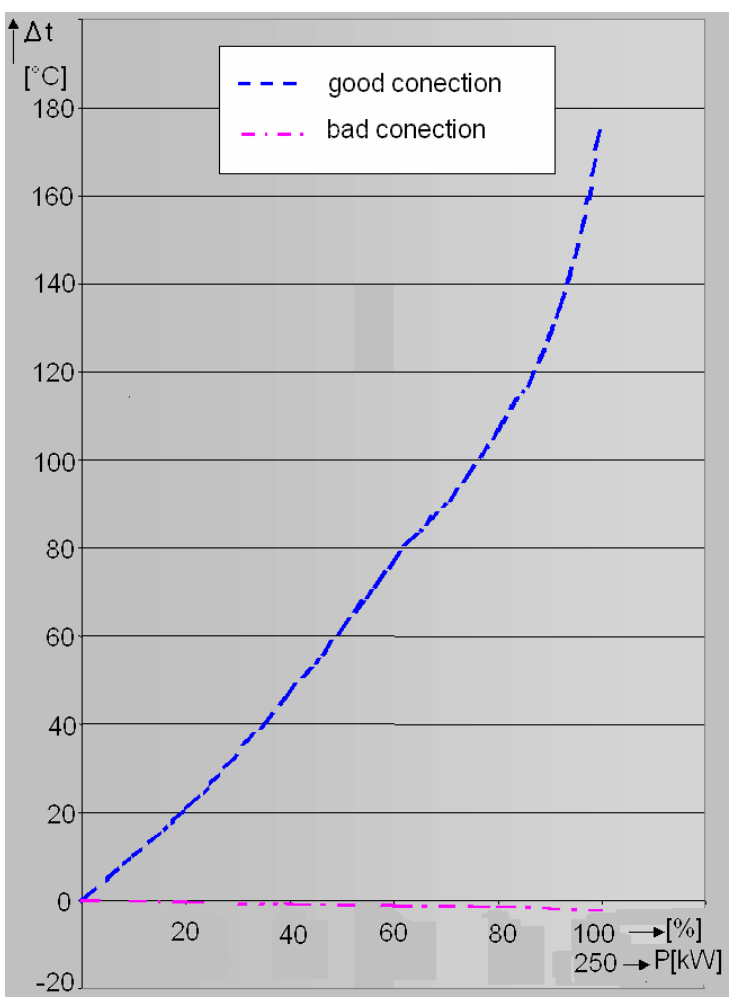

Fig 4. Relationship between temperature rise amount of connection and feeder line upon power $\Delta t=T_{s p}-T_{1}$

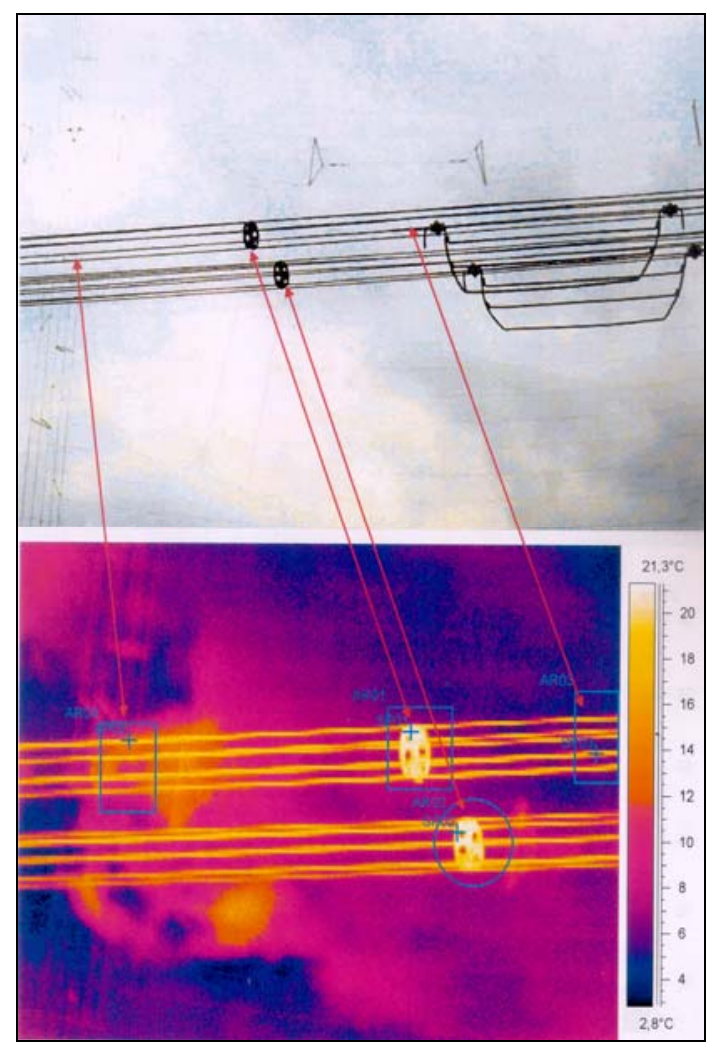

Fig 5. Thermogram of the junction feeder line - spacing collar, capacitor frame 


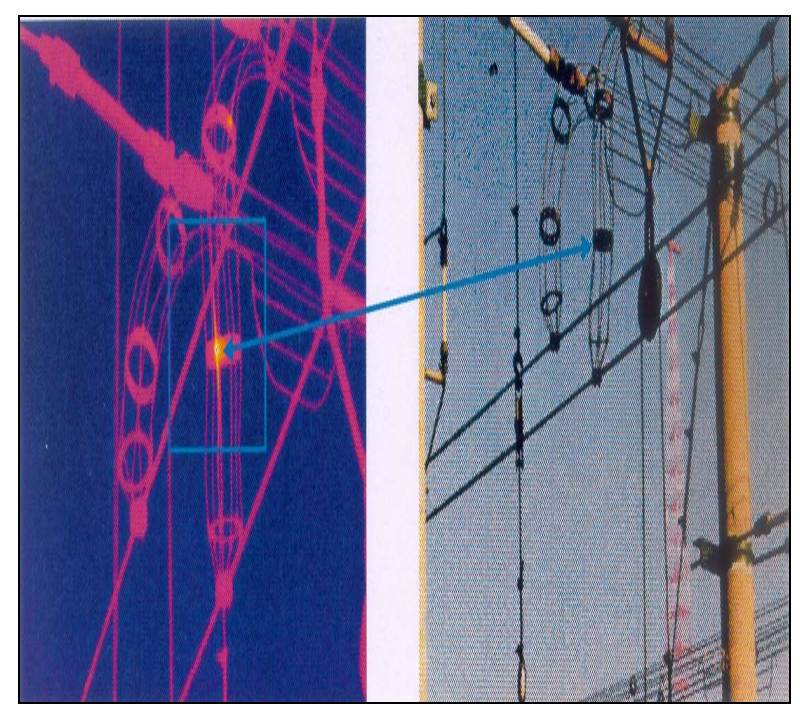

Fig 6. Thermogram of the junction feeder line - spacing collar

\section{Conclusion}

Thermovision diagnostics (thermodiagnostics) is a relatively young technical discipline classified to the branch of technical diagnostics. Its asset has been many times verified and in series of cases this diagnostics is irreplaceable or only with very difficulty replaceable by other diagnostic methods.

By the routine diagnostics and by early detection of defects $[4,5]$ in their initial stage it is possible to precede repairs on a large scale. The effectiveness and speed of measurements simplify and reduce substantially this process, the result of which is extensive economical effect. By the short contribution to the problems of diagnostics of radio transmitters of aerial systems we make reference to the possibilities of use of thermovision technique, which becomes at a fast rate a part of various branches as in Slovak republic as in all the other countries.

\section{References}

1. ŠEBOK, M.; ŠIMKO, M.; CHUPÁČ, M. Measurements of antenna systems transfer resistances. In 4th International Conference on Measurement. Measurement 2003 Smolenice, Slovak Republic, 2003, p. 399-402. ISBN 80967402-6-1.

2. Company TMV SS spol. s r. o. The new thermovision cameras of FLIR systems. Electrotechnics in Practice. Czech Republic, 2004, Vol 14, p. 70-72, ISSN 0862- 9730.

3. ZÁSKALICKÝ, P. Dynamic model of the reluctance stepping motor. In International Symposium on Electric Machinery. Prague, Czech Republic, 2005, p. 200-206.

4. FAKTOROVÁ, D. Microwave nondestructive testing of dielectric materials. Advances in Electrical and Electronic Engineering, 2006, Vol V, No 1-2, p. 230-233. ISSN 1336-1376.

5. FAKTOROVÁ, D. Interaction of solid materials inhomogenities with microwaves. In Proceedings of 13th International Conference Electronic Devices and Systems. Brno, Czech Republic, 2006, p. 388-393. ISBN 80-2143246-2. 